\title{
O Desenho na Gestalt-Terapia: A Versatilidade dos Traços em Interface com a Prática Clínica
}

\section{The Drawing in Gestalt-Therapy: The Versatility of the Lines Interfacing the Clinical Practice}

\section{EI Dibujo en Terapia Gestalt: La Versatilidad de los Trazos en Interfaz con la Práctica Clínica}

\author{
Evelyn Denisse Felix de Oliveira* \\ Universidade Católica Dom Bosco - UCDB, Campo Grande, Mato Grosso do Sul, \\ Brasil
}

\author{
Sonia Grubits** \\ Universidade Católica Dom Bosco - UCDB, Campo Grande, Mato Grosso do Sul, \\ Brasil
}

\begin{abstract}
RESUMO
Por meio de revisão integrativa de literatura, objetivou-se discutir a utilização do desenho na prática clínica em Gestalt-terapia. Consta do final dos anos de 1800 o primeiro estudo sobre os desenhos infantis. As teorias clássicas descrevem o desenvolvimento do grafismo por meio de estágios que são superados à medida que a criança se desenvolve. Na ciência psicológica, inicialmente, o desenho foi utilizado em testes psicológicos para medir aspectos cognitivos e, posteriormente, como técnica projetiva. Atualmente, ele também é utilizado como um meio para a investigação diagnóstica em diversas abordagens teóricas. Na Gestalt-terapia, o desenho pode ser utilizado como técnica, experimento e instrumento para o estabelecimento de vínculo, fundamentado no método fenomenológico. O desenho é uma importante ferramenta terapêutica que ao ser utilizada dentro de um processo psicoterapêutico consistente, fundamentado no vínculo de confiança e pautado no arcabouço teórico da Gestalt-terapia, é capaz de contribuir para o processo de atualização e de crescimento do cliente.
\end{abstract}

Palavras-chave: desenvolvimento infantil, prática clínica, grafismo.

\section{ABSTRACT}

Through an integrative literature review, the goal is to discuss the use of drawings on the clinical practice of Gestalt-therapy. The first study regarding children's drawings refers to the ending of the 1800's. The classical theories describe the development of the graphism through stages that are overcome as the child develops. In psychological science, initially, the drawing was used in psychological tests to measure cognitive aspects, and, further on, as a projective technique. Currently, it is also used as a manner of investigations for diagnosis in various theories. In Gestalt-therapy the drawing can be used as a technique, an experiment and an instrument to 
establish bonding, based on the phenomenological method. The drawing is an important therapeutic tool that, when used within a consistent psychotherapeutic process, founded on a tie of trust and based on the theoretical background of Gestalt-therapy, is capable of contributing to the update and growth process of the client.

Keywords: child development, clinical practice, graphism.

\begin{abstract}
RESUMEN
Por medio de una revisión integradora de literatura, se objetivó discutir la utilización del dibujo en la práctica en clínica en terapia Gestalt. Se pudo encontrar el primer estudio cerca los dibujos infantiles al final de los 1800 . Las teorías clásicas describen el desarrollo del grafismo a través de etapas que son rebasadas con el desarrollo de los niños. En la ciencia psicológica, inicialmente, el dibujo fue utilizado en pruebas psicológicas, para medir aspectos cognitivos $y$, después, como una técnica de proyección. Actualmente, también se pone como una forma de investigación diagnóstica en las teorías diversas. En la terapia Gestalt, el dibujo puede ser usado como técnica, para experimentación y instrumento de formación de vínculo, fundamentado por el método fenomenológico. El dibujo es una herramienta significativa que, cuando utilizada en un proceso psicoterápico consistente, fundamentado en un vínculo de confianza y basado en la teoría de la terapia Gestalt, puede contribuir con el proceso de actualización y crecimiento del cliente.
\end{abstract}

Palabras clave: desarrollo infantil, práctica clínica, grafismo.

Desde bem pequena, a criança já se aventura no universo dos rabiscos. Pais, pedagogos, psicólogos e artistas voltam-se para as primeiras produções da criança e cada um dispensa a elas diferentes olhares. A criança, por usa vez, pode estar alheia a tudo isso ou profundamente engajada, quando a atividade lhe faz algum sentido.

A criança quando desenha, de acordo com sua fase de desenvolvimento, vivencia experiências muito particulares "ela está nos oferecendo uma janela para o seu próprio entendimento em desenvolvimento do mundo e de seus relacionamentos com pessoas, coisas e locais importantes que a cercam" (Anning \& Ring, 2009, p. 9). Ao desenhar, a criança pode demonstrar suas angústias, pode se beneficiar de um momento autoterapêutico, pode tentar agradar, pode se comunicar e pode revelar que não está aware de si mesma.

Além disso, o desenho instrumentaliza a criança para o mundo, ao mesmo tempo que a protege dele. Os desenhos podem revelar as formas com as quais a criança almeja fazer contato com o mundo, na mesma medida em que proporciona soluções para que a criança suporte as frustrações advindas dele.

$\mathrm{Na}$ prática psicológica, os desenhos são largamente utilizados. Historicamente, os desenhos embasaram testes de medidas de inteligência e, posteriormente, tiveram sua importância reconhecida como técnicas de investigação da personalidade. Nessa seara, os testes de desenho são amplamente aplicados considerando a relativa 
aceitação das pessoas em realizar a tarefa, o baixo custo e a pseudo facilidade em manusear o instrumento.

$\mathrm{Na}$ clínica gestáltica, o desenho é um importante facilitador do diálogo, especialmente, no que diz respeito a auxiliar no estabelecimento de um bom contato consigo e com o mundo, (Mortola, 2006; Oaklander, 1980, 2009) além de ser fundamentado no método fenomenológico (Aguiar, 2014). O desenho apresenta pronunciada plasticidade, sendo utilizado não somente como instrumento de investigação, mas também como intervenção terapêutica e facilitador no estabelecimento do vínculo.

Por meio de revisão integrativa de literatura, objetivou-se discutir a utilização do desenho na prática clínica em Gestalt-terapia. Inicialmente, apresentar-se-á algumas teorias clássicas sobre a evolução do grafismo. Posteriormente, dissertar-se-á sobre a utilização do desenho na prática psicológica. Na sequência, discutirse-á a utilização do desenho na prática gestáltica e, por fim, apresentar-se-á as considerações finais, seguidas das referências utilizadas.

\section{A evolução do desenho}

Consta do final dos anos de 1800 o primeiro estudo sobre os desenhos infantis (Campos, 1987; Cox, 2012; Goodenough, 1961), embora tenha sido após o século o XX que o interesse e os estudos sobre o grafismo aumentaram exponencialmente, paralelamente aos avanços da psicologia do desenvolvimento (Anning \& Ring, 2009).

Para as crianças, desenhar é tão essencial quanto brincar (Kolck, 1984). Possibilitar experiências que envolvam desenhos contribui para o desenvolvimento holístico da criança, pois além do grafismo revelar o desenvolvimento de aspectos biológicos, cognitivos e emocionais, é uma atividade que prepara a criança para o desenvolvimento da linguagem escrita (Luria, 1988).

O desenvolvimento integral da criança e o meio afetam o grafismo infantil, ao mesmo tempo em que são expressos nele. É juntamente com o desenvolvimento da criança que o desenho evolui. Quando algo muda na forma com que a criança percebe o mundo por meio de projeções e imagens mentais, seu desenho também se transforma (Grubits, 2012).

Teóricos clássicos descreveram o desenvolvimento do desenho dividido em fases ou estágios, marcados pela superação de características cognitivas, criativas e motoras expressas no traçado. Lowenfeld e Britain (1970), partindo de uma perspectiva artística, preconizaram o desenvolvimento do grafismo associado ao desenvolvimento da criatividade na criança. Essa evolução ocorre na passagem de "o que" as crianças desenham para "o como" as 
crianças desenham. Com base nisso, os estágios descritos são garatujas (dividas em rabiscos desorganizados e rabiscos controlados), fase pré-esquemática, fase esquemática e fase do realismo (Lowenfeld, 1954).

O envolvimento da criança com o desenho ocorre por meio do contato com a própria experiência. Desenhar possui um fim em si mesmo, diferente do artista para quem o desenhar é o meio para um produto final (Lowenfeld, 1954). Desenhar, desta forma, equivale ao brincar. Uma criança pode passar muito tempo construindo uma fazendinha antes de propriamente brincar com ela, ou nem chegar a fazê-lo, contudo, desde a escolha do primeiro brinquedo para a construção, ela já estava brincando.

"O que" e "o como" as crianças desenham revelam aspectos de suas experiências. Enquanto realizam suas garatujas, crianças pequenas podem se comportar de formas diferentes. Algumas conseguem submergir na experiência, sendo sua própria fonte de motivação e aprovação, enquanto outras solicitam frequente e, até avidamente, o suporte objetivo e emocional do meio (Lowenfeld \& Britain, 1970).

Luquet, Piaget e Luria configuram a perspectiva cognitiva da evolução do desenho em que os processos cognitivos e de interação são evidenciados. Luquet foi o pioneiro da descrição da evolução do desenho da criança em estágios. Os estágios: realismo casual, realismo perdido, realismo intelectual e realismo visual foram descritos enquanto o autor observava os desenhos de sua filha ao longo dos anos (Luquet, 1969).

Influenciado por Luquet e com base em seus estágios do desenvolvimento humano, Piaget traçou cinco fases do desenvolvimento do desenho (Piaget, 1976). Garatujas desordenadas e ordenadas, compreendidas entre o período sensório-motor ( 0 a 2 anos) e início do período pré-operatório; fase pré-esquemática (fase pré-operatória de 2 a 7 anos); fase esquemática (operatório concreto de 7 a 10 anos); realismo (final das operações concretas); e pseudo naturalismo (Piaget, 1976).

Para Luria, um dos grandes pensadores do desenvolvimento infantil, o desenho compõe a pré-história da escrita. Inicialmente, por meio dos rabiscos e, posteriormente, pelo desenho, a criança desenvolve os pré-requisitos necessários para o desenvolvimento da linguagem grafada, e para isso o desenho da criança percorre as seguintes fases: pré-instrumental, fase topográfica, fase pictográfica e a fase simbólica (Luria, 1988).

À medida que a criança se desenvolve, ela demonstra por meio de fatores como cor, tamanho, forma e quantidade os estágios que são percorridos até o surgimento de uma relação funcional entre as linhas e rabiscos produzidos pela criança na tentativa de expressar algum significado, bem como demonstrar a aquisição da linguagem escrita. Quando a criança faz suas primeiras anotações escolares, ela já 
desenvolveu um repertório de habilidades que a capacitará a escrever em um curto período (Luria, 1988).

Mesmo quando ainda está desenvolvendo sua coordenação motora, a criança realiza rabiscos na chamada fase das garatujas. Nesta fase, as teorias clássicas são uníssonas em afirmar que a criança desenha por prazer, sem que esteja presente a intenção em representar a realidade. Não se observa ainda a presença de esquemas, tampouco a expressão ou projeção de emoções.

Contrário a isso, a perspectiva dinâmica e estética da evolução do desenho afirma que na fase dos rabiscos já existe a projeção de emoções e que a produção vai além do prazer motor.

A perspectiva dinâmica e estética também descrevem 0 desenvolvimento do grafismo em estágios: Estágio do Rabisco (imitativo e expressivo), Esteticismo Moral (Primário e Secundário), Rabiscos onomatopeicos, Rabiscos figurativos, Esteticismo prático e Esteticismo convencional, assemelhando-se às demais teorias clássicas, mas, diferentemente delas, afirma que desde a fase das garatujas já é possível observar expressões de estados emocionais (Quaglia, Longobardi, Iotti, \& Prino, 2015).

As teorias clássicas apresentam perspectivas que fragmentam a criança. Embora o proposto por cada uma delas encontre sua evidência, comprometem a aproximação a totalidade da criança. Contrário a isto, a visão gestáltica pressupõe que ao se adentrar no espaço vivencial da criança por meio do desenho, deve-se ter uma perspectiva ampla que busque integrar a criança em seus aspectos biológicos, psicológicos e sociais.

\section{O desenho na ciência psicológica}

No campo da Psicologia, o desenho mostra-se como importante recurso, seja como forma de investigação clínica, ou como teste psicológico. Nos dois casos, o grafismo revela ser um importante meio de acessar a psique humana.

Por seu caráter lúdico e despretensioso, a realização do desenho é facilmente aceita pela maioria das crianças, especialmente, as mais novas que não possuem ainda o compromisso com a replicação da realidade em suas produções. Capaz de revelar habilidades cognitivas, habilidades artísticas e conteúdos simbólicos, o desenho é uma forma de comunicação da criança, motivo esse que o torna um instrumento largamente utilizado no campo da Psicologia.

Inicialmente, o desenho serviu como base para reflexões a respeito de aspectos cognitivos, como nas propostas de Binet e Simon (Kolck, 1984) e as investigações de Lamprecht (Wechsler, 2003), posteriormente, influenciados pelo pensamento psicanalítico, Koppitz 
(1988), Di Leo (1991) e Hammer (1991) perceberam no desenho uma forma de investigar a personalidade.

Em 1923, Max Wertheimer, co-fundador da Psicologia da Gestalt (uma das teorias de base da Gestalt-terapia), apresentou seus estudos sobre a gênese da percepção visual de crianças, impulsionando estudos sobre a temática. Sob influência dos trabalhos de Wertheimer, Lauretta Bender, em meados de 1935, realizou os primeiros estudos sobre a maturação neurológica em crianças. Com base no fato de que para que uma criança reproduza graficamente algum traçado no papel ela necessita de maturação neurológica, em 1946, Bender publica o Teste Gestáltico Visomotor de Bender (Cunha, 2000; Ferreira, Feil, \& Nunes, 2009; Silva \& Nunes, 2007).

Atualmente, o teste de Bender encontra-se aprovado pelo SATEPSI (Sistema de Avaliação de Testes Psicológicos) como instrumento que avalia a maturação percepto-motora (Sisto, Noronha, \& Santos, 2006) juntamente com outros testes psicológicos que são baseados no grafismo e avaliam construtos como inteligência e criatividade de crianças como, respectivamente, o Desenho da Figura Humana Escala Sisto (Sisto, 2005), o Teste de Criatividade Figural Infantil (TCFI) (Nakano, Wechsler, \& Primi, 2011) e, o bastante utilizado, Casa-Árvore-Pessoa: Técnica projetiva de desenho - HTP (Buck, 2003), realizado com adultos e crianças.

Os desenhos também são utilizados como técnicas de investigação diagnóstica, como no procedimento de Desenhos-Estórias (D-E) que foi desenvolvido por Trinca, em 1972, com o objetivo de contribuir para a compreensão da dinâmica psíquica no diagnóstico psicológico. (Trinca, 1997). A atividade consiste em:

A técnica é bastante simples, baseando-se em um convite que se faz ao examinando de ir se aprofundando em sua vida psíquica, especialmente por meio de associações livres. Solicita-se que ele realize seguidamente uma série de cinco desenhos livres (cromáticos ou acromáticos), cada qual sendo estímulo para que conte uma história, associada livremente, logo após a realização de cada desenho. Tendo concluído cada desenho-estória, 0 examinando segue fornecendo esclarecimentos (fase do inquérito). (Trinca, 1997, p. 14).

Posteriormente, Trinca desenvolveu uma variação do $D-E$, o chamado procedimento Desenho de família-estória - DF-E, que além de conhecer a personalidade, tem como objetivo conhecer a natureza dos objetos internos parentais e fraternais, assim como os vínculos estabelecidos entre eles (Barbieri, 2013).

O procedimento D-E também é possível por meio de uma leitura fenomenológica-existencial. A proposta e a realização da atividade são as mesmas descritas por Trinca, mas o que a pessoa produz 
recebe o significado que the é dado no momento. Os temas escolhidos pronunciam o significado e os afetos que a pessoa relaciona com suas vivências, possibilitando ao psicólogo aproximarse da melhor forma possível da experiência do cliente, na maneira em que ela é (Ancona-Lopez, 2013).

O desenho é um recurso utilizado na Psicologia dentro das mais variadas fundamentações teóricas, especialmente, nas intervenções com crianças. Na prática com os adultos, sua utilização também é expressiva, embora os adultos apresentem mais frequentemente uma recusa inicial em desenhar.

\section{O desenho na perspectiva da Gestalt-terapia}

Gestalt-terapia é permissão para ser criativo (Zinker, 2007) e Perls demonstrou isso em sua prática em workshops que se assemelhavam a espetáculos, não só pelos resultados, mas também por suas performances. "Durante sua vida, Perls ampliou seu repertório com qualquer coisa que o ajudasse em seu objetivo de tornar seus pacientes, pessoas mais conscientes e responsáveis." (Naranjo, 1990, p. 56, tradução nossa). Muitas técnicas de expressão, supressão e integração (Naranjo, 1990), bem como experimentos como cadeira vazia (Ribeiro, 1994; Zinker, 2007) e trabalhos com sonhos (Lima, 2002; Ribeiro, 1994; Zinker, 2007) são utilizados de forma a caracterizar a Gestalt-terapia como meio criativo de promoção de crescimento e mudança.

De posse não só do criativo repertório instrumental da abordagem, mas também da sua própria criatividade, o Gestalt-terapeuta trabalha para "transpor barreiras que separam o eu verdadeiro dos papéis artificiais que representamos." (Rhyne, 2000, p. 38). As técnicas e os experimentos são catalisadores do processo psicoterapêutico. Aceleram o processo de reação sem alterar a natureza das partes envolvidas.

O desenho pode ser considerado como técnica, pois "facilita o acesso e a libertação de intensos afetos" (Sheperd, 1975, p. 303) e como experimento, pois se dirige ao eixo resistencial e o transforma em suporte flexível, isto é, "transforma o falar em fazer, as recordações estéreis e as teorizações em estar plenamente presente aqui, com a totalidade da imaginação, da energia e da excitação" (Zinker, 2007, p. 141) e ainda, segundo o autor, podem começar simplesmente como brincadeiras.

Mesmo utilizando-se das técnicas e de forma genial, Perls (1977) critica o seu uso arbitrário e afirma que: "Uma técnica é um truque. Um truque deve ser usado apenas em casos extremos." (p. 14). Alertando para o fato de que a aplicação da técnica pela técnica, embora possa causar uma certa energização, configura-se como uma 
"falsa terapia que impede o crescimento" (Perls, 1977, p. 14). O uso da técnica representa potencial terapêutico quando há um vínculo de confiança entre terapeuta e cliente, e quando o terapeuta possui sua prática assentada no arcabouço teórico filosófico da abordagem.

$O$ desenho pode ser sugerido com um objetivo específico quando 0 cliente relata que há um nó na garganta, por exemplo, ou pode surgir espontaneamente na interação no setting ao que, em seguida, pode solicitar-se que o cliente conte uma história sobre seu desenho. Ambas as intervenções poderão mobilizar o cliente, colocando-o em contato e promovendo a ampliação da consciência. "Desenhar sentimentos, pintar abstrações, repetir padrões gráficos, enfim, qualquer material expresso bidimensionalmente, pode ser fonte preciosa de informações e integração de conteúdos alienados." (Kiyan, 2009, p. 97).

A Gestalt-terapia é uma abordagem fenomenológica existencial que conta com a dialógica como norteadora da relação terapêutica. Martin Buber concebe duas palavras princípios na relação dialógica: Eu-Tu, que estrutura-se no "entre" e se fundamenta no mundo das relações, envolvendo a totalidade da pessoa e o respeito à alteridade; e EuIsso que refere-se à dimensão individual e objetificante do mundo, que se adotada de forma não intercambiável com Eu-Tu, pode resultar na utilização das pessoas com meio para um fim e não como um fim em si mesma (Buber, 1979).

A Gestalt-terapia prima pelo estabelecimento do vínculo de confiança, cabendo ao Gestalt-terapeuta portar-se de acordo com as características da relação dialógica: inclusão, que se configura como a entrada fenomenológica do terapeuta na vida do cliente; presença, em que o terapeuta mostra-se genuinamente como é, e não como gostaria ou deveria ser; compromisso com o diálogo, em que o terapeuta está disposto a dialogar na forma que for possível para o cliente; e não-exploração, em que o terapeuta jamais pode se utilizar do cliente como meio para um fim, tendo sempre que estar atento aos limites na relação terapeuta e cliente, exercendo sua profissão de forma teórica e tecnicamente adequada (Yontef, 1998).

Embora o desenho apresente tamanha versatilidade, é preciso que a proposta de tal atividade represente um potencial terapêutico no processo do cliente e nunca para preencher lacunas na sessão por conta da dificuldade de manejo do terapeuta, como o silêncio no atendimento do adulto, ou como forma de tentar fazer com que uma criança se acalme. Qualquer proposta realizada pelo terapeuta deve ter o objetivo claro de favorecer o processo do cliente e, além disso, o mesmo deve ser informado que o trabalho poderá ser interrompido a qualquer momento, caso seja essa a sua necessidade. Tal postura dialógica caracteriza-se como não-exploração (Yontef, 1998).

A relação dialógica é a base da relação psicoterapêutica em que o cuidado é a tônica. Os princípios fundamentais da relação Eu-Tu de 
Buber são muito significativos no trabalho com crianças. Terapeuta e cliente são pessoas separadas, e nenhum é superior ao outro, sendo responsabilidade do terapeuta manter a relação nesta configuração até o final do processo. Desta forma, o terapeuta deve ser autêntico, não manipulando no jogo, não agindo, por exemplo, como professor ou falando com a criança de forma condescendente (Oaklander, 2009), e a autora diz ainda:

Embora eu seja constantemente otimista sobre o potencial saudável da criança que chega em meu consultório, não nutro altas expectativas sobre ela. Eu a aceito como é. Eu respeito seu ritmo e, de fato, tento me juntar a ela. Dessa maneira, nosso relacionamento floresce. (Oaklander, 2009, p. 37, tradução nossa).

Acolher de forma dialógica pode parecer, inicialmente, uma tarefa pouco desafiadora para o terapeuta, se pensarmos nos clientes que são colaborativos e relativamente fluidos no processo psicoterapêutico. Contudo, alguns clientes podem portar-se de forma mais disfuncional, estabelecendo contato com o psicoterapeuta de forma desqualificadora, desconfiada ou desafiadora. As crianças também podem apresentar cristalizações na forma de fazer contato, escolhendo sempre o mesmo recurso para utilizar nas sessões, ou se comportando de forma regredida, agressiva ou silenciosa, pois "a criança chega para a consulta tendo a resistência como sua única aliada, como sua única forma de proteção." (Oaklander, 2009, p. 95, tradução nossa). Essas situações demandam uma postura dialógica do terapeuta que deverá estar presente, incluído e disponível para dialogar com o cliente na forma que é possível para ele no momento. No início do processo psicoterapêutico, as crianças podem se sentir constrangidas ou até ameaçadas em um ambiente novo com uma pessoa que não conhecem. Diante da recusa em explorar o ambiente, ou até mesmo de falar, a sugestão da realização de um desenho pode rapidamente transportar a criança para um local conhecido e menos ameaçador. Nestes momentos, por mais que a produção indique pontos para intervenções, limitamo-nos a explorar o desenho de forma a nos conectarmos com a criança, pois um bom vínculo dialogicamente construído é a base para o sucesso do processo terapêutico (Oaklander, 2009). Assim, se a criança desenhou um animal podemos demonstrar interesse em saber se ela tem animal de estimação, se gosta daquele animal etc.

Um menino com queixa de alergia na pele foi encaminhado para atendimento pelo médico dermatologista. Falando bem baixo e quase sem estabelecer contato visual comigo, acomodou-se em uma poltrona no canto da sala. Não demonstrou interesse pelo ambiente nem quis, a meu convite, explorar os brinquedos. Sugeri, então, que 
o menino realizasse um desenho, proposta que foi atendida de pronto, mais para se livrar da situação do que pelo interesse em realizar a atividade. $O$ menino desenhou a cabeça de um gato cinza, com grandes olhos amarelos, bigodes compridos e sem boca. Após a conclusão da produção, solicitei que ele dissesse o que havia desenhado, ao o que ele respondeu: "Um gato de olhos bem grandes". A partir disto, se seguiu uma detalhada descrição do gato pela própria criança, que foi acompanhada atentamente por mim. A criança tornou-se mais fluida naquele momento e, ao final da sessão, disse que estar ali não havia sido tão ruim.

Certamente, o fato de o gato não ter boca indicaria o caminho para uma intervenção de base fenomenológica, contudo, mais importante que qualquer outra intervenção, era a hospedagem da criança e o cultivo de um vínculo de confiança, e isso foi feito preservando-se a linguagem lúdica por meio do desenho. "A atitude fenomenológica é reconhecer e colocar entre parênteses (colocar de lado) ideias preconcebidas sobre o que é relevante." (Yontef, 1998, p. 218). Por outro lado, todo conteúdo relevante tende a se repetir, por isso, em momentos iniciais da psicoterapia, opta-se em deixar de intervir em alguns pontos em nome da garantia de um bom vínculo terapêutico.

Ao longo do processo, a criança ampliou sua fronteira de expressão até que suas queixas com a alergia foram minimizadas. A criança realizou inúmeros desenhos ao longo das sessões e, na última sessão, também quis fazê-los. Desenhou novamente o gato, só que dessa vez o gato tinha boca. Ao descrever os dois gatos, o menino imediatamente se identificou e disse que o primeiro gato era como ele era antes, mas que, assim como o segundo gato desenhado, ele agora "miava".

Embora seja mais comum a utilização de desenhos com crianças, com adultos o desenho também é um recurso potente. Os adultos tendem a resistir mais a desenhar do que as crianças, mas esclarecidos que o objetivo não é a apreciação de dons artísticos, eles também aderem às propostas de realização de desenho.

Com os adultos os desenhos podem ser utilizados no dia-a-dia da prática clínica, contudo, eles se mostram de grande valia em momentos em que 0 processo psicoterapêutico se encontra estagnado, ou quando o cliente está fixado em um determinado conteúdo. Um cliente vinha há algumas sessões se queixando do desconforto que sentia quando chegava em casa após o trabalho. As intervenções a nível verbal não tinham o auxiliado a dar-se-conta do que estava vivenciando. Ao ser convidado a desenhar o incômodo que mencionara, o cliente "desenhou" uma série de rabiscos coloridos. Na descrição do que havia produzido, o cliente chamou de um emaranhado de linhas e curvas. Sugeriu-se que o cliente olhasse para a sua produção e, em seguida, questionou-se se o cliente sentia-se mobilizado por algum sentimento, emoção ou sensação. 
Fazer questionamentos ao cliente sobre sua produção é um passo importante do método fenomenológico, que mesmo sendo descritivo, não exclui a utilização de perguntas e propostas que facilitem o acesso a "novos significados para o que foi descrito inicialmente, bem como criar novas formas de viver e encaminhar aquilo que emergia na sessão." (Aguiar, 2014, p. 151). Diante do questionamento, o cliente respondeu que sentia-se agonizando, que era como se aquelas linhas o estivessem sufocando. Em um exercício de presentificação, embasado no método fenomenológico, o cliente deu-se-conta de que se sentia soterrado pelas demandas familiares e que da mesma forma, em outros campos de sua vida, tendia a colocar as necessidades dos outros acima das suas.

Inúmeras são as possibilidades de intervenções baseadas no desenho, contudo, o método norteador dessas propostas é o método fenomenológico que, se opondo à linguagem interpretativa e prescritiva, caracteriza-se pela descrição (Aguiar, 2014).

Com base no método fenomenológico, o Gestalt-terapeuta não se utiliza de hipóteses, ele auxilia o cliente a encontrar o sentido do vivido, pois: "O método fenomenológico dispensa a apresentação a priori das hipóteses, pois, na sua essência, a Fenomenologia é ciência descritiva dos fenômenos expressivos da realidade como ela é." (Petrelli, 2001, p. 40).

A interpretação ocorre após uma exaustiva sequência de observação, descrição, redução fenomenológica e checagem, pois quem atribui o significado à experiência é o cliente.

Independentemente da forma ou contexto, o método fenomenológico embasa todo trabalho com desenho em Gestalt-terapia que, além de ser o método básico da Gestalt-terapia, garante a autenticidade do vivido pelo cliente e impede que projeções do psicoterapeuta afetem o trabalho, comprometendo o processo.

\section{Considerações finais}

Desenhar é um ato inerente ao ser humano e prepara a pessoa para a vida. Ao desenhar, a criança se diverte de forma prazenteira, realiza treinos sociais, desenvolve habilidades cognitivas e motoras, além de expressar estados emocionais. Quando adulta, a pessoa consegue, por meio do desenho, permitir o acesso aos conteúdos mais escondidos e, com isso, pode acessar também novas modos de estar no mundo de forma mais funcional.

Como uma técnica, experimento ou instrumento facilitador do estabelecimento do vínculo o desenho se mostra como promovedor do contato, da ampliação da consciência e do crescimento. Os limites adequados devem ser observados para que de fato o cliente possa se favorecer da experiência. 
O desenho é um instrumento dialógico que favorece o encontro existencial, que é uma prerrogativa da Gestalt-terapia. Nesse encontro, a relação é paritária e, embora terapeuta e cliente tenham funções definitivamente distintas, não existe uma relação de importância ou de poder entre eles. Terapeuta e cliente encontram uma profunda conexão e nela o cliente gentilmente permite que o terapeuta adentre em seu universo, e o terapeuta, por sua vez, respeitosamente se dirige ao encontro sem a priori e sem expectativas, possibilitando, assim, que o que for genuíno prevaleça. O desenho é uma importante ferramenta terapêutica que, se utilizada dentro de um processo psicoterapêutico consistente, fundamentado no vínculo de confiança e pautado no arcabouço teórico da Gestaltterapia, é capaz de contribuir para o processo de atualização e de crescimento do cliente.

O presente trabalho não esgota, em definitivo, a apresentação das possibilidades de utilização do desenho na prática clínica em Gestaltterapia. Novas pesquisas se fazem necessárias de forma a contribuir teórica e tecnicamente com a abordagem.

\section{Referências}

Aguiar, L. (2014). Gestalt-terapia: Teoria e prática. São Paulo, SP: Editora Summus.

Ancona-Lopez, S. (2013). O uso do procedimento desenhos-estórias na abordagem fenomenológica-existencial. In W. Trinca (Org.), Procedimento de desenhos-estórias: formas derivadas, desenvolvimentos e expansões (pp. 161-176). São Paulo, SP: Vetor Editora.

Anning, A., \& Ring, K. (2009). Os significados dos desenhos de crianças. Porto Alegre, RS: Artmed.

Barbieri, V. (2013). Laços e embaraços: o procedimento de desenhos de família com estórias na compreensão cruzada dos psicodinamismos de mãe e filha. In W. Trinca (Org.), Procedimento de desenhos-estórias: formas derivadas, desenvolvimentos e expansões (pp. 231-276). São Paulo, SP: Vetor Editora.

Buber, M. (1979). Eu e Tu. São Paulo, SP: Cortez \& Moraes.

Buck, J. N. (2003). H-T-P: Casa - Árvore - Pessoa. Técnica Projetiva de Desenho: Manual e Guia de Interpretação. São Paulo, SP: Vetor Editora.

Campos, D. M. S. (1987). O teste do desenho como instrumento de diagnóstico da personalidade. Petrópolis, RJ: Editora Vozes.

Cox, M. (2012). Desenho da criança. São Paulo, SP: Martins Fontes.

Cunha, J. A. (2000) Psicodiagnóstico V. Porto Alegre, RS: Artmed. 
Di Leo, J. H. (1991). A interpretação do desenho infantil. Porto Alegre, RS: Artes Médicas.

Ferreira, R. B., Feil, C. F., \& Nunes, M. L. T. (2009). O Teste Gestáltico Visomotor de Bender na avaliação clínica de Crianças. PsicoUSF, 14(2), 185-192. doi: 10.1590/S141382712009000200007

Goodenough, F. L. (1961). Test de inteligência infantil por meio del dibujo de la figura humana. Buenos Aires: Editorial Paidós.

Grubits, S., Tardivo, L. S. de La P. C., Bonfin, T., Vizzotto, M., Freire, H. B. G., Noriega, J. A. V. \& Arias, G. (2012). Semelhanças e diferenças nos desenhos de crianças indígenas brasileiras. Avaliação Psicológica, 11(3), 461-474. Recuperado de http://pepsic.bvsalud.org/scielo.php?script=sci_arttext\&pid=S1 677-04712012000300012\&lng=pt\&tIng =pt

Hammer, E. F. (1991). Aplicação clínica nas técnicas projetivas. São Paulo, SP: Casa do Psicólogo.

Kiyan, A. M. M. (2009). O gosto do experimento: possibilidades clínica em Gestalt-Terapia. São Paulo, SP: Editora Altana.

Kolck, O. L. V. (1984). Testes projetivos gráficos no diagnóstico psicológico. São Paulo, SP: EPU.

Koppitz, E. M. (1988). Avaliação psicológica do desenho da figura humana em crianças escolares. Porto Alegre, RS: Artes Médicas.

Lima, A. P. F. (2002). Gestalt e sonhos. São Paulo, SP: Summus Editorial.

Lowenfeld, V. (1954). A criança e sua arte. São Paulo, SP: Mestre Jou.

Lowenfeld, V., \& Britain, W. L. (1970). Desenvolvimento da Capacidade Criadora. São Paulo, SP: Mestre Jou.

Luquet, G. (1969). O desenho infantil. Barcelona: Porto Civilização.

Luria, A. R. (1988). O Desenvolvimento da escrita na criança. In L. S. Vigotski (Ed.), Linguagem, desenvolvimento e aprendizagem (pp. 143-190). São Paulo, SP: Ícone - Editora da Universidade de São Paulo.

Mortola, P. (2006). Em método Oaklander: aprender Gestalt infantojuvenil com juegos y arte. Santiago: Editorial Cuatro Vientos.

Nakano, T. C., Wechsler, S. M., \& Primi, R. (2011). Teste de Criatividade Figural Infantil: Manual técnico. São Paulo, SP: Editora Vetor.

Naranjo, C. (1990). La Vieja e novíssima Gestalt: actitud y pratica. Santiago: Editorial Cuatro Ventos.

Oaklander, V. (1980). Descobrindo crianças: a abordagem gestáltica com crianças e adolescentes. São Paulo, SP: Summus Editorial.

Oaklander, V. (2009). El tesoro escondido: la vida interior de niños y adolescentes. Santiago: Editorial Cuatro Vientos. 
Perls, F. (1977). Gestalt-terapia explicada. São Paulo, SP: Summus Editorial.

Petrelli, R. (2001). Fenomenologia: teoria, método e prática. Goiânia, GO: Editora da UCG.

Piaget, J. (1976). A equilibração das estruturas cognitivas. Rio de Janeiro, RJ: Zahar Editores.

Quaglia, R., Longobardi, C., Iotti, N. O., \& Prino, L. E. (2015). A new theory on children's drawings: Analyzing the role of emotion and movement in graphical development. Infant Behavior \& Development, 39(1), 81-91. Recuperado de https://www.researchgate.net/publication/274085624_A_new_t heory_on_children's_drawings_Analyzing_the_role_of_emotion _and_movement_in_graphical_development

Rhyne, J. (2000). Arte e Gestalt. São Paulo, SP: Summus Editorial.

Ribeiro, J. P. (1994). Gestalt-terapia: o processo grupal. São Paulo, SP: Summus Editorial.

Sheperd, I. L. (1975). Limitações e cautelas na abordagem gestaltista. In J. Fagan \& I. L. Sheperd (Eds.), Gestalt-terapia: Teoria, técnicas e aplicações (pp. 303-309). Rio de Janeiro, RJ: Zahar Editores.

Silva, R. B. F., \& Nunes, M. L. T. (2007). Teste Gestáltico Visomotor de Bender: revendo sua história. Avaliação Psicológica, 6(1), 77-88. Recuperado de http://pepsic.bvsalud.org/pdf/avp/v6n1/v6n1a10.pdf

Sisto, F. F. (2005). Desenho da figura humana: Escala Sisto. São Paulo, SP: Vetor Editora.

Sisto, F. F., Noronha, A. P. P., \& Santos, A. A. A. (2006). Teste Gestáltico Visomotor de Bender - Sistema de Pontuação Gradual (B-SPG). São Paulo, SP: Vetor Editora.

Trinca, W. (1997). Formas tradicionais de aplicação. In W. Trinca (Org), Formas de investigação clínica em psicologia (pp. 1326). São Paulo, SP: Vetor Editora.

Wechsler, S. M. (2003). DFH-III - O desenho da figura humana: Avaliação do desenvolvimento de crianças brasileiras. Campinas, SP: Impressão Digital.

Yontef, G. (1998). Processo, diálogo e awareness. São Paulo, SP: Summus Editorial.

Zinker, J. (2007). Processo criativo em Gestalt-terapia. São Paulo, SP: Summus Editorial.

\section{Endereço para correspondência}

\section{Evelyn Denisse Felix de Oliveira}

Rua 14 de julho, 5147, BL D12, ap. 34, Condomínio Vale do Sol II, Centro, CEP 79011-470, Campo Grande - MS, Brasil

Endereço eletrônico: evelyn_psi@hotmail.com 


\section{Sonia Grubits}

Av. Mato Grosso, 759, Centro, CEP 79002-231, Campo Grande - MS, Brasil Endereço eletrônico: idakublikowski@pucsp.br

Recebido em: 13/10/2019

Reformulado em: 05/02/2020

Aceito em: 08/02/2020

\section{Notas}

* Doutoranda em Psicologia pela Universidade Católica Dom Bosco. Gestaltterapeuta, Gestalt-terapeuta de crianças, atualmente, é professora da Universidade Católica Dom Bosco.

** Doutorado em Saúde Mental pela Faculdade de Ciências Médicas da UNICAMP. Doutorado com status de pós-doutorado por Paris 8 Sorbonne, França. Pósdoutorado em Saúde Mental no Trabalho pela UNICAMP. Atualmente é orientadora técnica do Instituto de Psicologia Médica de Mato Grosso, professora e pesquisadora da UCDB.

O estudo teórico se refere a reflexões da pesquisa do doutorado da primeira autora, Evelyn Denisse Felix de Oliveira.

Financiamento: a primeira autora possui Bolsa-taxa CAPES.

Este artigo de revista Estudos e Pesquisas em Psicologia é licenciado sob uma Licença Creative Commons Atribuição-Não Comercial 3.0 Não Adaptada. 